\title{
Role of land-surface temperature feedback on model performance for the stable boundary layer
}

\author{
A. A. M. Holtslag • G. J. Steeneveld • \\ B. J. H. van de Wiel
}

Received: 31 August 2006 / Accepted: 9 July 2007 / Published online: 17 August 2007

(C) Springer Science+Business Media B.V. 2007

\begin{abstract}
At present a variety of boundary-layer schemes is in use in numerical models and often a large variation of model results is found. This is clear from model intercomparisons, such as organized within the GEWEX Atmospheric Boundary Layer Study (GABLS). In this paper we analyze how the specification of the land-surface temperature affects the results of a boundary-layer scheme, in particular for stable conditions. As such we use a well established column model of the boundary layer and we vary relevant parameters in the turbulence scheme for stable conditions. By doing so, we can reproduce the outcome for a variety of boundary-layer models. This is illustrated with the original set-up of the second GABLS intercomparison study using prescribed geostrophic winds and land-surface temperatures as inspired by (but not identical to) observations of CASES-99 for a period of more than two diurnal cycles. The model runs are repeated using a surface temperature that is calculated with a simple land-surface scheme. In the latter case, it is found that the range of model results in stable conditions is reduced for the sensible heat fluxes, and the profiles of potential temperature and wind speed. However, in the latter case the modelled surface temperatures are rather different than with the original set-up, which also impacts on near-surface air temperature and wind speed. As such it appears that the model results in stable conditions are strongly influenced by non-linear feedbacks in which the magnitude of the geostrophic wind speed and the related land-surface temperature play an important role.
\end{abstract}

Keywords Atmosphere-land interaction - Boundary-layer parameter study · GABLS . Model evaluation - Model intercomparison study $\cdot$ Land-surface temperature feedback . Stable boundary layer

\footnotetext{
A. A. M. Holtslag $(\varangle)$ • G. J. Steeneveld · B. J. H. van de Wiel

Meteorology and Air Quality Section, Wageningen University, Wageningen,

The Netherlands

e-mail: Bert.Holtslag@wur.nl
} 


\section{Introduction}

In the stable boundary layer over land many small-scale physical processes occur, such as turbulent mixing, radiation divergence, gravity waves (e.g., Mahrt 1999; Holtslag 2006). These processes need to be represented in an effective way in an atmospheric model, and the current understanding of these processes in the stable boundary layer is rather limited (e.g., Delage 1997; Beljaars and Viterbo 1998; Mahrt 1998; Edwards et al. 2006; Steeneveld et al. 2006b). This is relevant for the forecasting of surface and air temperatures, wind speed and direction, the surface fluxes and the boundary-layer depth, and it affects the forecasting of frost and fog episodes (e.g. Clark and Hopwood 2001), and on the dispersion of pollutants and trace gases (e.g. Salmond and McKendry 2005).

To enhance the understanding and to improve the representation of the atmospheric boundary layer in models for weather forecasting, air quality and climate research, frequent model evaluation and intercomparison studies are organized (e.g., Lenderink et al. 2004, Cuxart et al. 2006; Steeneveld et al. 2007). Overall the aim of such studies is to identify strengths and weaknesses of models in comparison with observations (e.g., Poulos et al. 2002) and large-eddy simulations (LES) (e.g. Beare et al. 2006; Kumar et al. 2006).

Usually the intercomparison studies with atmospheric column (1D) models are done with simplified boundary conditions and forcing conditions, such as prescribing a constant geostrophic wind and a prescribed surface temperature (tendency). So far this has also been the approach within the GEWEX Atmospheric Boundary Layer Study (GABLS); see Cuxart et al. (2006) for an overview of the 1D model results for the first GABLS model intercomparison, and Svensson and Holtslag (2006) for the initial results of the second GABLS model intercomparison. Note that evaluation of boundary-layer models with a prescribed surface temperature has been also a typical approach for column models (e.g. Rao and Snodgrass 1979; Delage 1997), as well as large-eddy simulation models (e.g. Beare et al. 2006; Basu et al. 2006).

Instead of prescribing the surface temperature, one may alternatively prescribe the surface sensible heat flux. This has been a useful approach for cases studies over sea and daytime conditions over land (e.g. Lenderink et al. 2004; Kumar et al. 2006), but for nighttime (stable) conditions over land the surface heat flux depends strongly on surface-layer turbulence. Kumar et al. used LES to study the diurnal cycle of the atmospheric boundary layer and they encountered numerical instabilities in stable conditions. At present it is not clear whether this is related to the subgrid closure or to the heat flux boundary condition utilized. In addition, the surface temperature and the surface heat flux are interdependent and are strongly related to the magnitude of the geostrophic wind (e.g. Estournel and Guedalia 1985; Gopalakrishnan et al. 1998; Derbyshire 1999; Delage et al. 2002; van de Wiel et al. 2003; Steeneveld et al. 2006a, b). Thus neither the surface temperature nor the surface heat flux, is a true external boundary condition, at least not for stable conditions (van de Wiel et al. 2007).

It also appears that the results for both the first and second GABLS model intercomparisons show significant variability in the surface fluxes, and the atmospheric wind speed and temperature profiles, despite the relatively simple surface temperature description (and forcing conditions). It is supposed that this is directly related to the different parameterizations of the various models, but it is unknown to what extent the surface temperature boundary condition has an impact on this.

In this study we explore the impact of the surface temperature feedback on the variability of model results. As such, our aim is to investigate to what extent the degree of variability among the model results is influenced by prescribing the surface temperature and not solving for the surface energy balance. The set-up of the second GABLS case is used to study more 
than two diurnal cycles of the boundary layer over land under clear skies, but we focus on variability created in stable conditions. Some preliminary results of this study were presented by Holtslag et al. (2006).

\section{Set-up intercomparison and model description}

In the current study we use a first-order closure model and vary the parameters in the turbulence scheme for stable conditions in a reasonable range to mimic the apparent variability among boundary-layer models. Thus, at first, model runs are performed with a prescribed surface temperature as inspired by (but not identical to) the observations in CASES-99 (Poulos et al. 2002) and as described in the GABLS2 case description (Svensson and Holtslag 2006). Second, the model runs are repeated, but using an interactive prognostic heat budget equation for the surface temperature.

For our study we use the coupled land-surface boundary-layer model of Duynkerke (1991) with the extensions of Steeneveld et al. (2006b). The reference model has 50 logarithmically distributed layers with the first atmospheric model level at $2 \mathrm{~m}$. The roughness lengths for heat $z_{o h}$ and momentum $z_{\text {om }}$ are given by $3 \mathrm{~mm}$ and $30 \mathrm{~mm}$, respectively. Compared to the reference second GABLS study, the surface boundary condition for specific humidity has been altered by introducing a constant canopy resistance of $800 \mathrm{~s} \mathrm{~m}^{-1}$ (to represent the dry conditions during CASES-99, Steeneveld et al. 2006b). Below a brief discussion of the model assumptions is given.

\subsection{Turbulence parameterization}

The turbulent fluxes of momentum and heat are described by local diffusion for both the surface layer and the SBL. The eddy diffusivity $K$ is given by a first-order closure, which for the whole stable boundary layer can be written as:

$$
K_{x}=\frac{\ell^{2}}{\phi_{m} \phi_{x}}\left|\frac{\partial \vec{V}}{\partial z}\right| .
$$

Here subscript $x$ refers to heat $(h)$ or scalar mixing, and subscript $m$ reflects momentum. The length scale $\ell$ is given by:

$$
\frac{1}{l}=\frac{1}{k z}+\frac{1}{\lambda_{0}}
$$

where $k=0.4$ is the Von Karman constant, and $\lambda_{0}$ is the asymptotic mixing length (which is infinite in the reference case). Furthermore, the non-dimensional gradients for heat and momentum in stable conditions are given by (Duynkerke 1991):

$$
\phi_{x}(\zeta)=\frac{k z}{X_{*}} \frac{\partial \bar{X}}{\partial z}=1+\beta_{x} \zeta\left(1+\frac{\beta_{x}}{\alpha_{x}} \zeta\right)^{\alpha_{x}-1} .
$$

In Eq. $3 \zeta=\mathrm{z} / \Lambda$, where $\Lambda$ is the local Obukhov length.

For the reference model we use $\beta_{m}=5, \beta_{h}=5$, and $\alpha_{m}=\alpha_{h}=0.8$. Note that this has been validated with observations at Cabauw (Duynkerke 1991), and for CASES-99 (Steeneveld et al. 2006b; Baas et al. 2006). For unstable conditions the original model by Duynkerke (1991) is used for simplicity, although it neglects the impact of non-local mixing by convection (e.g. Holtslag and Moeng 1991). 


\subsection{Soil and land-surface scheme}

In the interactive model runs, the soil temperature evolution is calculated by solving the diffusion equation (using a grid spacing of $10 \mathrm{~mm}$ ) and the heat flux $G$ through the vegetation is calculated from:

$$
G-\left(1-f_{v e g}\right) K^{\downarrow}=r_{g}\left(T_{v e g}-T_{s 0}\right),
$$

where $K^{\downarrow}$ is the incoming shortwave radiation, $T_{v e g}$ represents the vegetation surface temperature, and $T_{s 0}$ is the soil temperature just below the vegetation (at $z=0 \mathrm{~m}$ ). As reference values we have $f_{\text {veg }}=0.9$ and $r_{g}=5.9 \mathrm{~W} \mathrm{~m}^{-2} \mathrm{~K}^{-1}$, which are consistent with the observations of CASES-99 (Steeneveld et al. 2006b). Initial soil and surface temperatures are also taken from the CASES-99 observations.

Subsequently, the evolution of $T_{\text {veg }}$ is computed by solving the surface energy budget for the vegetation layer:

$$
C_{v} \frac{\partial T_{v e g}}{\partial t}=Q^{*}-G-H-L_{v} E,
$$

where $C_{v}$ is the heat capacity of the vegetation layer per unit of area $\left(C_{v}=2,000 \mathrm{~J} \mathrm{~m}^{-2} \mathrm{~K}^{-1}\right.$, van de Wiel et al. 2003), $Q^{*}$ is the net radiation, $H$ is the sensible heat flux and $L_{v} E$ is the latent heat flux. $Q^{*}$ is calculated by adopting the Garratt and Brost (1981) radiation scheme.

Note that Eqs. 4 and 5 provide a rather strong coupling of the atmosphere to the vegetated land-surface for the current parameter setting (see also Steeneveld et al. 2006b).

\subsection{Model parameter settings}

To study the impacts of parameter values on the model results, reference runs are made for coupled and uncoupled cases with alternative permutations in some of the parameter settings for stable conditions. The parameter modifications are chosen such that they cover a realistic range in comparison with existing models of the stable boundary layer (such as described in Cuxart et al. 2006). The alternate values of the parameters to be used in the Eqs. 1-3 are:

$-\alpha_{\mathrm{m}}=\alpha_{\mathrm{h}}=0.95$

$-\beta_{\mathrm{m}}=\beta_{\mathrm{h}}=3$ or 4.7

$-\lambda_{0}=15,50,100,250 \mathrm{~m}$;

- $\lambda_{0}=\varepsilon \frac{u_{*, \text { local }}}{N}$, with $\varepsilon=0.8,1.3,2$.

In addition model runs are made:

- with the use of 30 or 20 layers in the model set-up (instead of 50);

- where the height of the first level (z1) is placed at $10 \mathrm{~m}$ above the surface rather than $2 \mathrm{~m}$ in the reference case;

- with the inclusion of a value for the molecular diffusivity in one of the runs.

In all model runs the roughness length and the canopy resistance are constant (as in Steeneveld et al. 2006b), and the geostrophic wind is taken at a reference value of $9.5 \mathrm{~m} \mathrm{~s}^{-1}$ (as in Svensson and Holtslag 2006). To study the impact of wind speed on the results (e.g., Estournel and Guedalia 1985; Derbyshire 1999; Gopalakrishnan et al. 1998), additional runs are done with a reduced geostrophic wind (see below). Note that it is not our intention to do a full parameter study here. The impact of changing the asymptotic length scale $\left(\lambda_{0}\right)$ was already discussed for the current model by Steeneveld et al. (2006a). 

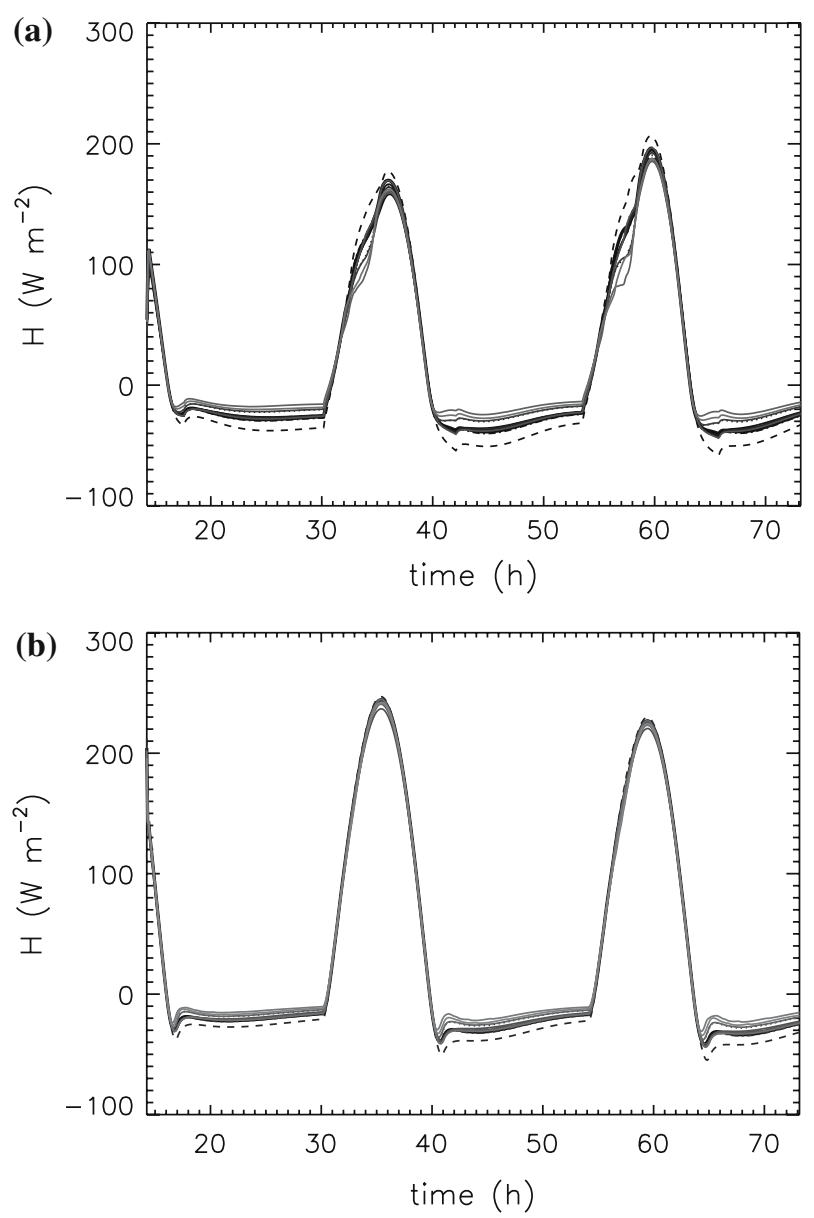

Fig. 1 Time series (in hours commencing at $1400 \mathrm{LT}$ ) of model results for the sensible heat flux in a model intercomparison study with (a) prescribed surface temperatures, and (b) by solving the surface energy budget

\section{Results}

The model results for all parameter permutations are first presented for the sensible heat flux (Fig. 1), friction velocity (Fig. 2), and boundary-layer height (Fig. 3). The latter is defined as the height where the stress is $5 \%$ of its surface value divided by 0.95 (as in Cuxart et al. 2006). In each figure the upper sub-frame of the figure (labelled a) indicates the results achieved with the uncoupled model (using prescribed surface temperature) and in (b) the results are given achieved by solving the energy budget equation. The local starting time in the model runs is 1400 LT on October 22, 1999 (rather than 1600 LT in the GABLS2 runs). The duration of all runs is $59 \mathrm{~h}$ (so that the axis of all the figures indicates 14 until $73 \mathrm{~h}$, covering a period of 2.5 diurnal cycles).

Overall the variety of results in the upper frames (Figs. 1a, 2a, 3a) is comparable to the variety within the GABLS2 intercomparison study in stable conditions for the uncoupled models (see also Svensson and Holtslag 2006). Thus we have a range of -10 to $-40 \mathrm{~W} \mathrm{~m}^{-2}$ 

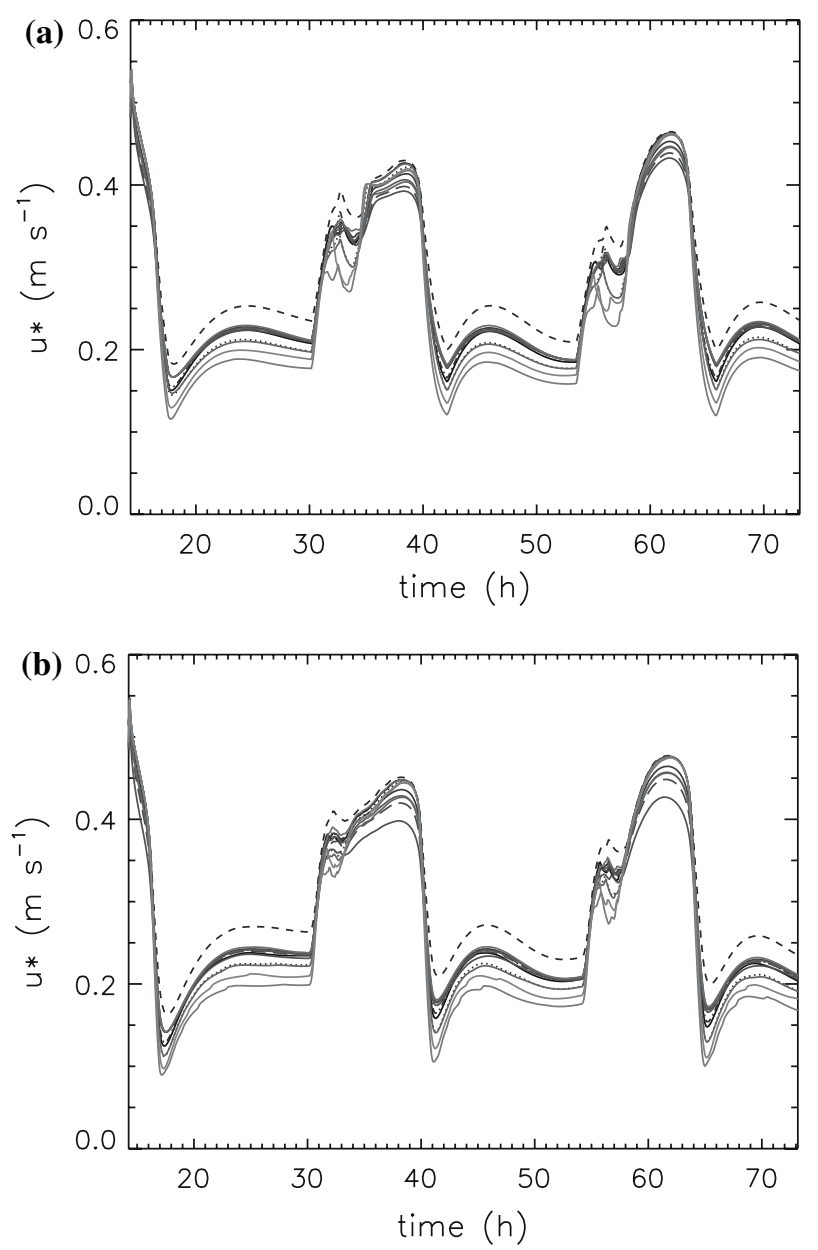

Fig. 2 As Fig. 1 for friction velocity

for the sensible heat flux, a range of 0.19 to $0.25 \mathrm{~m} \mathrm{~s}^{-1}$ for friction velocity and boundarylayer depths varying between 80 and $220 \mathrm{~m}$ (all indicated values apply for the variables at the end of the first night e.g. at the indicated time of $30 \mathrm{~h}$ in the figures). The variability is a result of the range of parameters chosen above and the impact is apparently sufficient to mimic the different parameterizations for stable conditions in the models used within GABLS2.

Next we repeat all model runs and allow for surface feedback using Eqs. 4 and 5. The results for the coupled model runs are given in the lower frames (Figs, 1b, 2b, 3b). Now we have a range of -10 to $-25 \mathrm{~W} \mathrm{~m}^{-2}$ for the sensible heat flux, a range of $0.20-0.26 \mathrm{~m} \mathrm{~s}^{-1}$ for friction velocity and boundary-layer depths between 100 and $270 \mathrm{~m}$ (again all indicated values apply for the variables at the end of the first night e.g. at the time of $30 \mathrm{~h}$ ). Thus it appears that the variety of model results is smaller for the sensible heat flux in the coupled case, in particular. At the same time the variability appears to be somewhat larger for friction velocity and boundary-layer depth, which seems to be related to the larger variability in the near-surface air temperature and wind speed (see Figs. 5 and 6 below). 

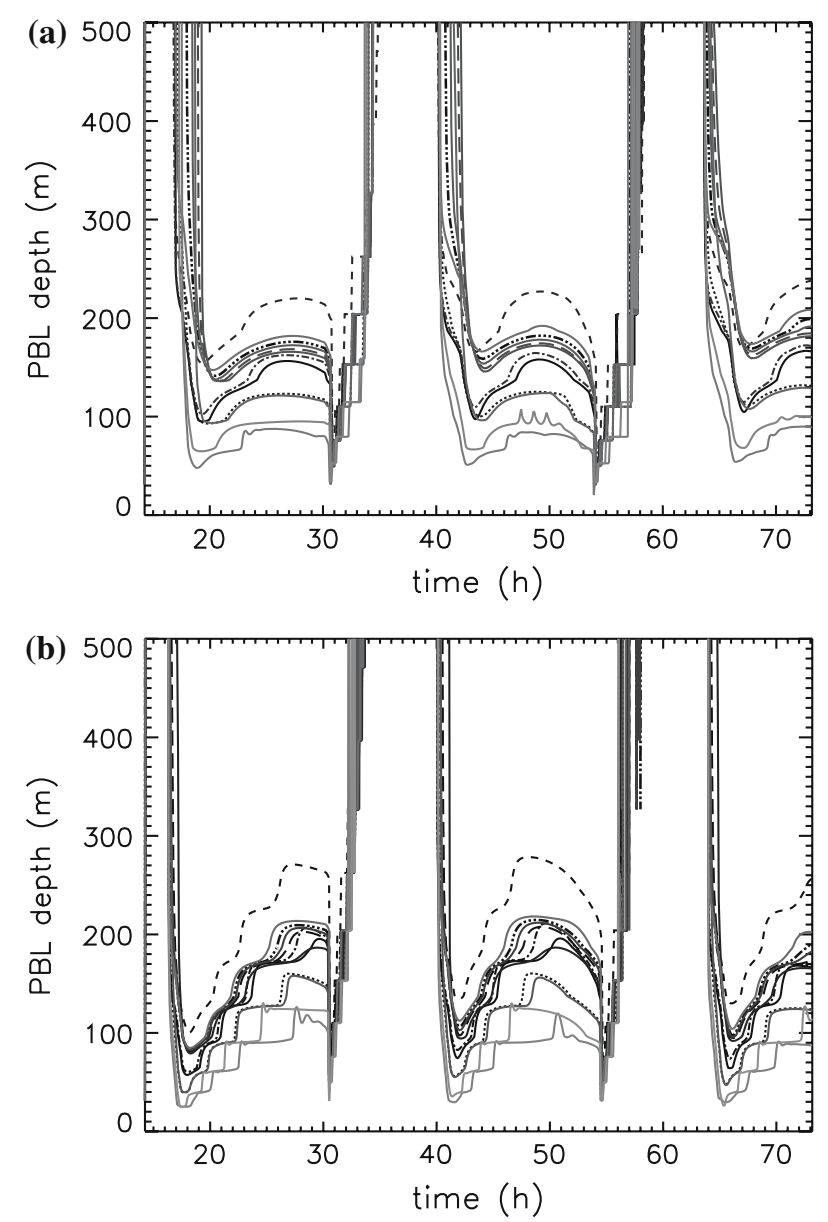

Fig. 3 As Fig. 1 for boundary-layer depth

During daytime the sensible heat fluxes are rather similar for all model runs within one category (either coupled or uncoupled), but the maximum values differ. In addition, due to the coupling the sensible heat fluxes show a smoother behaviour in the morning hours as compared with the uncoupled results (Fig. 1). Thus, surface feedback is influencing the model results and is also able to compensate for some variation in the model parameter values. Note also that the variability in the friction velocities of the first night remains during the morning hours in the uncoupled runs, but not so much in the coupled case.

In Fig. 4 the surface temperatures are given as specified for the uncoupled case (the dashdotted line), and the temperatures as calculated in the various interactive model runs (various grey lines). It is seen that the latter values are quite different from each other (in particular at night). It is also important to note that the surface temperature by the ensemble of coupled model runs is clearly different from the specified temperature in the uncoupled case. This affects also the absolute values and the range of air temperatures (given at $2 \mathrm{~m}$ ), and the nearsurface wind speeds (given at $10 \mathrm{~m}$ ). This can be seen in the time series for these variables in Figs. 5 and 6, respectively. 


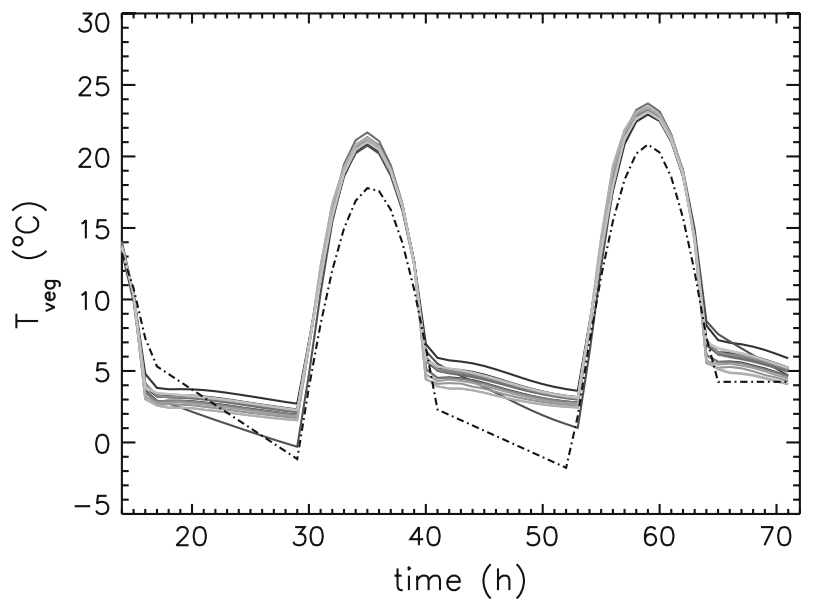

Fig. 4 Time series of modelled surface temperature for coupled runs. Dash-dotted line: prescribed surface temperature in the uncoupled case

To further understand this issue, we show in Figs. $7 \mathrm{a}$ and $7 \mathrm{~b}$ the dependence of the sensible heat flux on the potential temperature difference between the surface and the lowest atmospheric model level for given wind speed at that level (at $z=2 \mathrm{~m}$ ). As such we have integrated Eq. 3 for heat and momentum in the surface layer for the reference model parameter settings in stable conditions. In addition, the symbols refer to the outcome of the variety of model runs with perturbed parameter values for the first night, either in the uncoupled case (Fig. 7a) or in the coupled case (Fig. 7b). The indicated lines apply for the reference model and show values for the wind speed at the lowest atmospheric model level (at $2 \mathrm{~m}$ ). The figures are inspired by earlier works of van de Wiel (2002) and Delage et al. (2002).

In Figs. $7 \mathrm{a}$ and $7 \mathrm{~b}$ it is seen that for lower wind speeds, the curves show a maximum. In fact two regimes can be distinguished, namely the 'well-behaved regime' (at the left-hand side of the maximum) where sensible heat flux is proportional to the potential temperature difference for a given wind speed. This occurs in weakly to moderately stable conditions in which turbulence is sufficiently strong and can maintain itself. At the right-hand side of the maximum, turbulence is suppressed by stability effects so that the exchange decreases and consequently also the sensible heat flux decreases if the potential temperature increases (see also discussion by Holtslag and De Bruin 1988; De Bruin 1994). As such, a positive feedback loop can be established resulting in diminishing turbulence and large temperature gradients.

The results indicate that for a given potential temperature difference and wind speed, a large variation in sensible heat flux can occur due to the different model parameter settings for stable conditions (see Sect. 2). The differences impact clearly on the model results for all model variables as indicated above. Interestingly, it also appears that the results for the uncoupled model runs with perturbed parameter settings (Fig. 7a) show larger absolute values for sensible heat flux for given temperature difference and wind speed than the results of the coupled runs shown in Fig. 7b. In addition, the uncoupled model runs show no maximum for the heat flux, while the coupled model runs do show this. This explains the smaller range of sensible heat fluxes and also the smaller range of variability among model results in the coupled case. The chosen boundary condition has therefore a clear impact on which stability regime is entered. With a prescribed surface temperature condition, the model does not enter the regime with the positive feedback. 

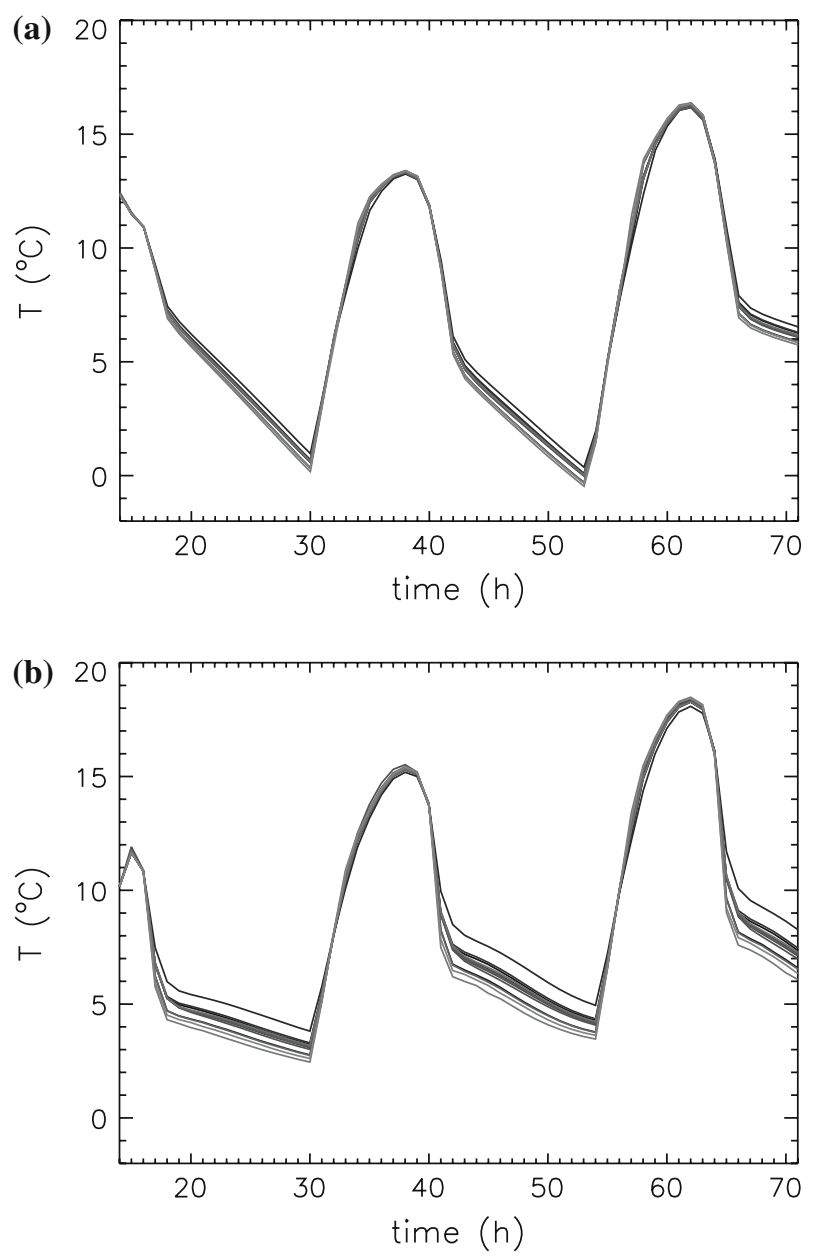

Fig. 5 Time series of the model air temperature at $2 \mathrm{~m}$ for (a) prescribed surface temperatures, and (b) by solving the surface energy budget

In Fig. 7a also a cluster of points is visible at the right-hand side. It appears that this results from the additional model run with lower vertical resolution (see Sect. 2). However, in the coupled case the outcome of the latter run is in more agreement with the other results (Fig. 7b). Overall the findings illustrate that the coupling of the boundary-layer scheme to the land-surface clearly has an impact on the model findings, and this is due to the many feedbacks in this highly nonlinear system (see also McNider et al. 1995).

Forecasted atmospheric profiles for potential temperature and wind speed magnitude after $12 \mathrm{~h}$ are given in Figs. 8 and 9 (valid for local nighttime conditions at 0200 on October 23, 1999). Similar range of results is achieved for longer forecasting times during the night. To illustrate the variability in potential temperature and wind speed magnitude, we have calculated the mean square difference (or variance) of the ensemble of model results. Figures 10 and 11 show the outcome of this. Again a distinction is made in uncoupled (upper frames) and coupled cases (lower frames). In all figures the variances are plotted for a height 

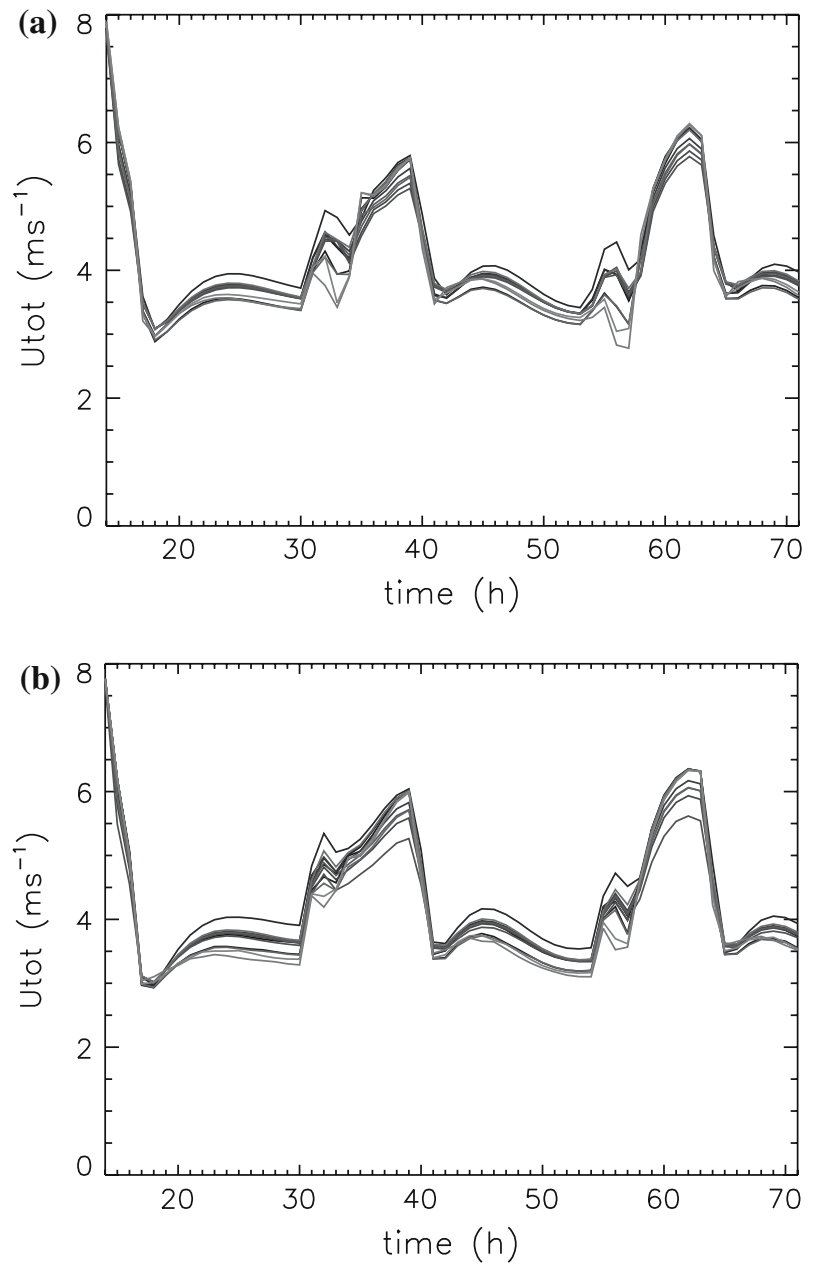

Fig. 6 Time series of the model wind speed at $10 \mathrm{~m}$ for (a) prescribed surface temperatures, and (b) by solving the surface energy budget

up to $300 \mathrm{~m}$ and for the complete forecast period. It is clear from these figures that the strongest variability occurs for potential temperature and wind speed in the stable boundary layer at the end of the night in the morning transition hours. This is true for both the coupled and uncoupled cases, although with different magnitudes. During daytime the variability among the models is much less, because of the impact of convective mixing in such conditions.

The variances in the SBL occur over the same depth although with different magnitudes. It is also clear that the variability increases with forecasting time, which is to be expected in this nonlinear system (e.g., McNider et al. 1995). During the second night the maximum variance is $11.2 \mathrm{~K}^{2}$, while in the first night this is only $4 \mathrm{~K}^{2}$ (factor 3 smaller) for the uncoupled model runs (Fig. 10a). The variability in the model results is rather different for potential temperature and the wind speed magnitude by comparing their results for the coupled and uncoupled cases. For potential temperature the variability decreases with about a 

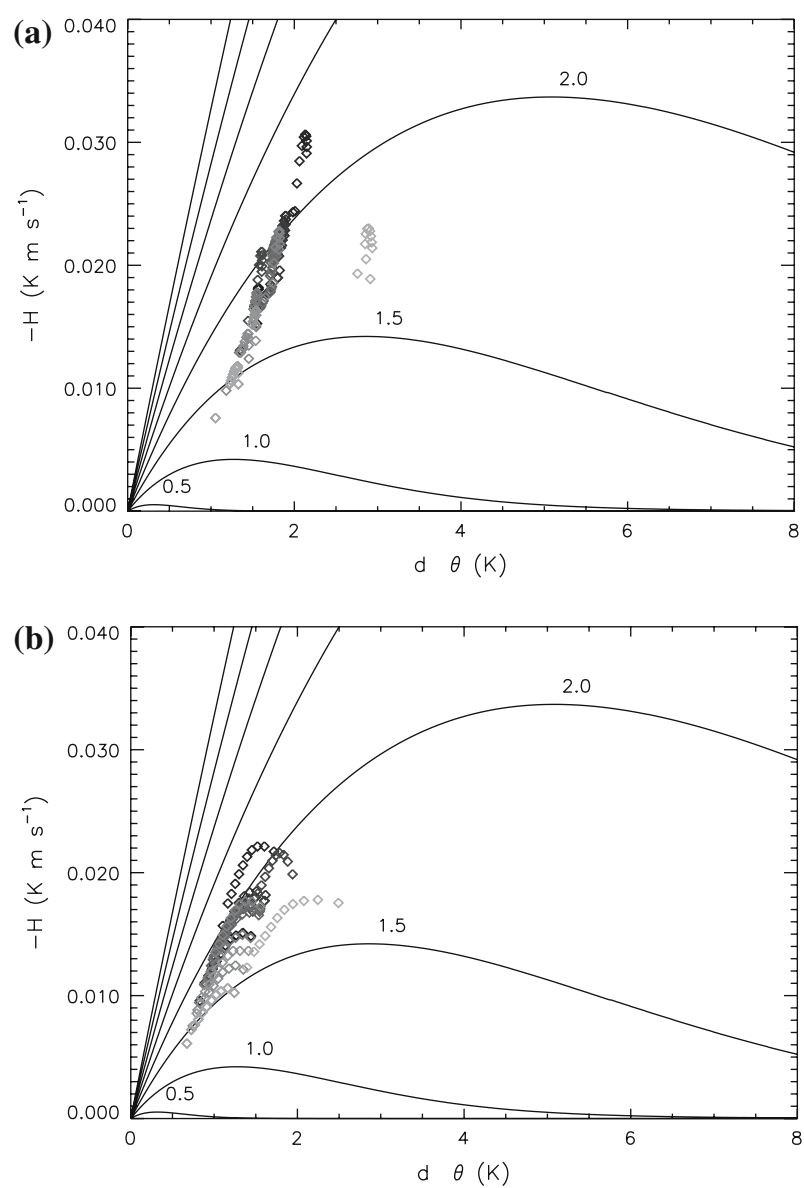

Fig. 7 The variation of sensible heat flux $H\left(\right.$ in $\mathrm{Kms}^{-1}$ ) with potential temperature difference near the surface for the reference model and perturbed model results (various symbols) for (a) prescribed surface temperatures, and (b) by solving the surface energy budget. The full lines refer to the wind speed with an interval of $0.5 \mathrm{~m} \mathrm{~s}^{-1}$ at a model height of $2 \mathrm{~m}$

factor of 4 for the coupled case, and for the wind speed magnitude the variance decreases by $30 \%$.

By repeating the model experiments with a lower geostrophic wind of $4.8 \mathrm{~m} \mathrm{~s}^{-1}(50 \%$ of the reference value), we find overall similar characteristics. However, the magnitudes for the variances of the predicted profiles for potential temperature and for the wind speed are typically smaller in the case of the lower geostrophic wind, both in the coupled and uncoupled model runs (not shown). Thus there is a clear dependence of the model results on both the surface temperature and the geostrophic wind speed, confirming earlier findings by Estournel and Guedalia (1985) and Gopalakrishnan et al. (1998).

From the findings presented, it is apparent that the treatment of the surface temperature boundary condition affects strongly the outcome of the boundary-layer model results and their variety. By repeating the uncoupled model runs with a specified surface temperature as given by the ensemble mean value of the interactive runs, we achieve basically the same 
Fig. 8 The profiles of a) wind speed magnitude and $b$ ) potential temperature up to $500 \mathrm{~m}$ for a $12 \mathrm{~h}$ forecast
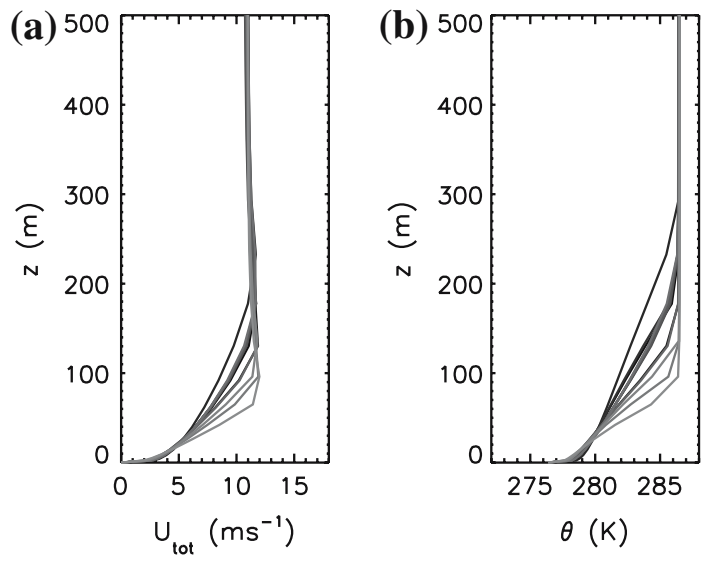

Fig. 9 As Fig. 8 but for the coupled runs

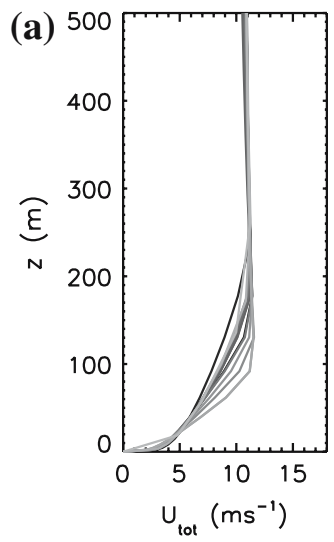

variety of model outputs for the potential temperature and wind as for the coupled cases. This confirms that in model evaluation studies the surface temperature should be taken consistent with the value of the geostrophic wind (although this is likely to be model dependent).

\section{Discussion and conclusion}

In this paper we have studied the impact of the surface temperature on the variability of results using an atmospheric boundary-layer model. First, it appears that most of the variability seen in the second GABLS model intercomparison case for stable conditions can be reproduced by taking one model and choosing alternative parameter values in a reasonable range. Second, the variety of model results is less when coupled to the land-surface. This is particularly true for the surface sensible heat flux, and the profiles of wind and temperature. However, we find that in the coupled case the realized surface temperatures are clearly different from the specified value of the uncoupled model case study. In addition we find sensitivity of the model results to the magnitude of the geostrophic wind speed. 

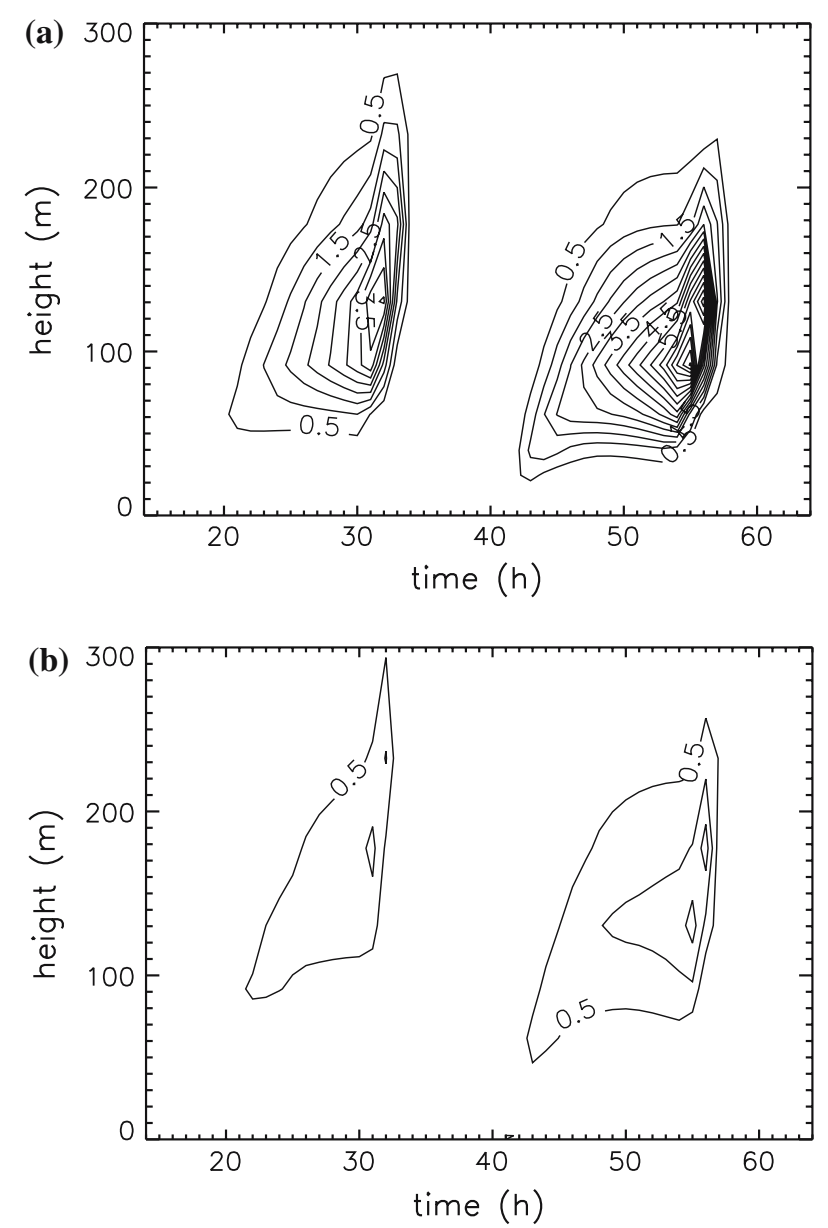

Fig. 10 Contour plot of variance of the predicted potential temperature in a prescribed (a) and coupled (b) case

From the coupled model results we find that surface feedback can compensate for some of the variety introduced by changing model parameters. Thus the evaluation of boundary-layer models is less critical when coupled to the land-surface, in particular for the nighttime boundary layer over land (see also Holtslag et al. 2006). However, this conclusion seems to depend on the combination of the specified geostrophic wind speed and the surface temperature. In fact these variables are related in the stable boundary layer over land (e.g., Estournel and Guedalia 1985; Derbyshire 1999; Gopalakrishnan et al. 1998 among many other studies).

Steeneveld et al. (2006b) were able to achieve realistic surface temperatures with a coupled model set-up similar to that used here, but by using a more detailed specification of the variation of the geostrophic wind as a function of time. In contrast, in the current study we use a constant geostrophic wind over time as was specified in the GABLS2 model intercomparison case. Then in combination with the specified values for the surface temperature, a larger range of results is found. If a surface temperature is chosen that is consistent with the magnitude of the geostrophic wind then a smaller variation of model results is found. 

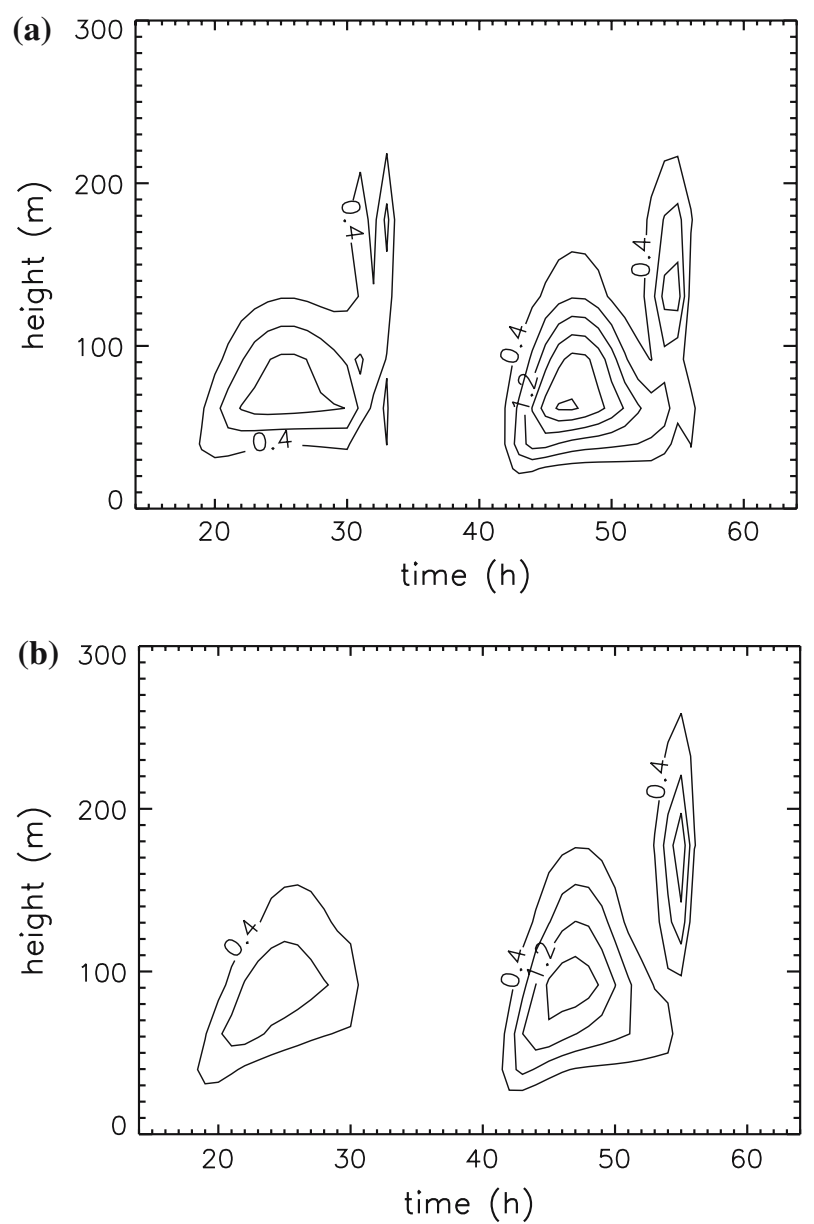

Fig. 11 As Fig. 10 for the model variance of wind speed magnitudes

In conclusion, the intercomparison and evaluation of boundary-layer models are not as simple and straightforward as it may seem. Our results herein indicate that variability among model results in stable conditions is not only related to the different parameterizations, but also to what extent the applied surface temperature forcing and the magnitude of the geostrophic wind are consistent with each other. This conclusion may also be relevant for large-eddy simulation studies (e.g., Beare et al. 2006; Kumar et al. 2006).

Acknowledgements The work was inspired by many discussions with colleagues at our Department and in the GABLS and GLASS/LOCO communities. We acknowledge the suggestions and comments on drafts of this paper by Gunilla Svensson (Stockholm University), Bart van den Hurk (KNMI), Jordi Vila (Wageningen Univ.), Sukanta Basu (Texas Tech Univ.), and the reviewers.

\section{References}

Baas P, Steeneveld GJ, van de Wiel BJH, Holtslag AAM (2006) Exploring Self-correlation in flux-gradient relationships for stably stratified conditions. J Atmos Sci 63:3045-3054 
Basu S, Porte-Agel F, Foufoula-Georgiou E, Vinuesa JF, Pahlow M (2006) Revisiting the local scaling hypothesis in stably stratified atmospheric boundary-layer turbulence; an integration of field and laboratory measurements with large-eddy simulations. Boundary-Layer Meteorol 119:473-500

Beare R, MacVean M, Holtslag A, Cuxart J, Esau I, Golaz J-C, Jimenez M, Khairoutdinov M, Kosovic B, Lewellen D, Lund T, Lundquist J, McCabe A, Moene A, Noh Y, Raasch S, Sullivan P (2006) An intercomparison of large-eddy simulations of the stable boundary layer. Boundary-Layer Meteorol 118:247-272

Beljaars ACM, Viterbo p (1998) Role of the boundary layer in a numerical weather prediction model. In: Holtslag AAM, Duynkerke PG (eds) Clear and cloudy boundary layers. Royal Netherlands Academy of Arts and Sciences, Amsterdam, $372 \mathrm{pp}$

Clark PA, Hopwood WP (2001) One-dimensional site-specific forecasting of radiation fog. Part I: model formulation and idealized sensitivity studies. Meteorol Appl 8:279-286

Cuxart J, Holtslag AAM, Beare RJ, Bazile E, Beljaars A, Cheng A, Conangla L, Ek M, Freedman F, Hamdi R, Kerstein A, Kitagawa H, Lenderink G, Lewellen D, Mailhot J, Mauritsen T, Perov V, Schayes G, Steeneveld GJ, Svensson G, Taylor P, Weng W, Wunsch S, Xu K-M (2006) Single-column model intercomparison for a stably stratified atmospheric boundary layer. Boundary-Layer Meteorol 118:273-303

DeBruin HAR (1994) Analytic solutions of the equations governing the temperature fluctuation method. Boundary-Layer Meteorol 68:427-432

Delage Y (1997) Parameterising sub-grid scale vertical transport in atmospheric models under statically stable conditions. Boundary-Layer Meteorol 82:23-48

Delage Y, Bartlett PA, McCaughey JH et al (2002) Study of 'soft' night-time surface-layer decoupling over forest canopies in a land-surface model. Boundary-Layer Meteorol 103:253-276

Derbyshire SH (1999) Boundary layer decoupling over cold surfaces as a physical boundary instability. Boundary-Layer Meteorol 90:297-325

Duynkerke PG (1991) Radiation fog: a comparison of model simulation with detailed observations. Mon Wea Rev 119:324-341

Edwards JM, Beare RJ, Lapworth AJ (2006) Simulation of the observed evening transition and nocturnal boundary layers: single column modelling. Quart J Roy Meteorol Soc 132:61-80

Estournel C, Guedalia D (1985) Influence of geostrophic wind speed on atmospheric nocturnal cooling. J Atmos Sci 42:2695-2698

Garratt JR, Brost RA (1981) Radiative cooling effects within and above the nocturnal boundary layer. J Atmos Sci 38:2730-2746

Gopalakrishnan SG, Sharan M, McNider RT, Singh MP (1998) Study of radiative and turbulent processes in the stable boundary layer under weak wind conditions. J Atmos Sci 55:954-960

Holtslag AAM (2006) GEWEX atmospheric boundary layer study (GABLS) on stable boundary layers. Boundary-Layer Meteorol 118:243-246

Holtslag AAM, De Bruin HAR (1988) Applied modeling of the nighttime surface energy balance over Land. J Appl Meteorol 27:689-704

Holtslag AAM, Moeng CH (1991) Eddy diffusivity and countergradient transport in the convective atmospheric boundary layer. J Atmos Sci 48:1690-1698

Holtslag AAM, Steeneveld GJ, van de Wiel BJH (2006) Exploring variability of model results in the GEWEX atmospheric boundary layer study (GABLS). In: 17th symposium on boundary layers and turbulence, San Diego, USA, 22-25 May. American Meteorological Society, Boston, Paper 8.2. http://ams.confex.com/ams/pdfpapers/110553.pdf

Kumar V, Kleissl J, Meneveau C, Parlange MB (2006) Large-eddy simulation of a diurnal cycle of the atmospheric boundary layer: atmospheric stability and scaling issues. Water Resour Res 42:18

Lenderink G, Siebesma AP, Cheneit S, Ihrons S, Jones CG, Marquet P, Muller F, Olmera D, Calvo J, Sanchez E, Soares PMM (2004) The diurnal cycle of shallow cumulus clouds over land: a single-column model intercomparison study. Quart J Roy Meteorol Soc 130:3339-3364

Mahrt L (1998) Stratified atmospheric boundary layers and breakdown of models. Theo Comp Fluid Phys 11:263-279

Mahrt L (1999) Stratified atmospheric boundary layers. Boundary-Layer Meteorol 90:375-396

McNider RT, England DE, Friedman MJ, Shi X (1995) Predictability of the stable atmospheric boundary layer. J Atmos Sci 52:1602-1614

Poulos GS et al (2002) CASES-99: a comprehensive investigation of the stable nocturnal boundary layer. Bull Amer Meteorol Soc 83:555-581

Rao KS, Snodgrass HF (1979) Some parameterization of the nocturnal boundary layer. Boundary-Layer Meteorol 17:15-28

Salmond JA, McKendry IG (2005) A review of turbulence in the very stable boundary layer and its implications for air quality. Prog Phys Geogr 29:171-188 
Steeneveld GJ, van de Wiel BJH, Holtslag AAM (2006a) Modeling the arctic stable boundary layer and its coupling to the surface. Boundary-Layer Meteorol 118:357-378

Steeneveld GJ, van de Wiel BJH, Holtslag AAM (2006b) Modeling the evolution of the atmospheric boundary layer coupled to the land surface for three contrasting nights in CASES-99. J Atmos Sci 63:920-935

Steeneveld GJ, Mauritsen T, de Bruijn EIF, Vilà-Guerau de Arellano J, Svensson G Holtslag AAM (2007)

Evaluation of limited area models for the representation of the diurnal cycle and contrasting nights in CASES99. J Appl Meteor Clim (in press)

Svensson G, Holtslag (2006) Single column modeling of the diurnal cycle based on CASES99 data - GABLS second intercomparison project. In: 17th symposium on boundary layers and turbulence, San Diego, USA, 22-25 May. American Meteorological Society, Boston, Paper 8.1. http://ams.confex.com/ams/pdfpapers 1110758.pdf

van de Wiel BJH (2002) Intermittency and oscillations in the stable boundary layer over land. PhD thesis. Wageningen University, no. 3319, 129 pp

van de Wiel BJH, Moene AF, Hartogensis OK, de Bruin HAR, Holtslag AAM (2003) Intermittent turbulence and oscillations in the stable boundary layer over land, Part III: a classification for observations during CASES99. J Atmos Sci 60:2509-2522

van de Wiel BJH, Moene AF, Steeneveld GJ, Hartogensis OK, Holtslag AAM (2007) Predicting the collapse of turbulence in stably stratified boundary layers. Flow, Turbulence Combust (in press) 